\title{
Article \\ Preliminary Experimental Trial of Effects of Lattice Fence Installation on Honey Bee Flight Height as Implications for Urban Beekeeping Regulations
}

\author{
Tomonori Matsuzawa ${ }^{1,2}$ (D) and Ryo Kohsaka ${ }^{1, *(D)}$ \\ 1 Graduate School of Environmental Studies, Nagoya University, Nagoya 464-8601, Japan; \\ matsuzawa.tomonori@b.mbox.nagoya-u.ac.jp \\ 2 Biodiversity Research Center, IDEA Consultants, Inc., Yokohama 224-0025, Japan \\ * Correspondence: kohsaka@hotmail.com
}

check for updates

Citation: Matsuzawa, T.; Kohsaka, R. Preliminary Experimental Trial of Effects of Lattice Fence Installation on Honey Bee Flight Height as Implications for Urban Beekeeping Regulations. Land 2022, 11, 19.

https://doi.org/10.3390/

land11010019

Academic Editors: Le Yu and Marta Debolini

Received: 9 December 2021

Accepted: 21 December 2021

Published: 23 December 2021

Publisher's Note: MDPI stays neutral with regard to jurisdictional claims in published maps and institutional affiliations.

Copyright: (C) 2021 by the authors. Licensee MDPI, Basel, Switzerland. This article is an open access article distributed under the terms and conditions of the Creative Commons Attribution (CC BY) license (https:// creativecommons.org/licenses/by/ $4.0 /)$.

\begin{abstract}
Urban beekeeping has gained salience because of its significance in biodiversity conservation and community building. Despite this, beekeeping practices in urban areas have received negative perceptions from residents, which stem from public safety concerns. There is, therefore, a need to enhance and/or work on appropriate rules for maximizing the profits while minimizing the risks. Amongst the present regulations, the installation of barriers and setbacks is the most common rule for public safety. However, only a limited number of empirical studies have reported on their effective location and height. Thus, in this study, an experimental apiary was set up with different types of barriers installed with varying distances to observe and measure flyway patterns of honey bees. We used a 3D laser scanner, which obtained 8529 points of highly accurate flight location data in about five hours. Results showed that the heights $(1.8$ and $0.9 \mathrm{~m})$ of the barriers installed were effective in increasing the flight altitudes. The distance of the fence, which was installed as close as $1 \mathrm{~m}$ from the hives, was effective as well. These findings, which showed that barriers and setbacks are effective, can have regulatory implications in designing apiaries in urban spaces, where location is often restricted.
\end{abstract}

Keywords: urban beekeeping; regulations; barrier; setback; 3D laser scanner; remote sensing; fence location

\section{Introduction}

Beekeeping in the context of agroforestry systems is vital for supportinglocallivelihoods (e.g., production of honey and beeswax), particularly in forest villages [1,2]. As part of the biosphere, bees are considered major pollinators, influencing ecological relationships, genetic variation in the plant community, floral diversity, specialization and evolution, and ecosystem conservation and stability [2,3]. In agricultural settings, bees are essential for crop pollination, and pollination using bees is currently practiced globally (USA, Australia, New Zealand and Europe) [2,4]. For instance, in Canada, beekeepers are paid to provide pollination services for hybrid canola seed productions [5]. Despite their socio-ecological importance, there has been a decline in bee colonies over the last decade, which has renewed interest in honey bees, particularly in relation to colony collapse disorder [6]. This in turn has resulted in the global expansion of urban keeping [7], and scientists have argued that keeping bees in urban settings might be more beneficial for their survival due to the reduced exposure to agricultural pesticides and limited assortment of plants for foraging [8,9]. Furthermore, urban beekeeping has gained salience because of its significance in biodiversity conservation, food production, and community building in urban areas [10-12].

In recent years, increasing numbers of municipalities are actively adopting urban beekeeping as part of their environmental policies. For instance, in 2019, the German state of Bayer enacted Bavaria's nature protection law, which encourages the keeping of 
bees in urban areas [13]. In Los Angeles and New York, they changed their respective ordinances to allow urban beekeeping [14]. Moreover, pollinator-friendly cities, which promote the protection of pollinating insects including honey bees and the environment are on the rise [13]. However, as beekeeping practices in urban areas increase, concerns from local residents have also grown, stemming from property disputes (e.g., nuisance, trespass claims) by neighbors, negligence accusations against beekeepers, and challenges to the legal status of the honey bee by local communities [15]. Thus, there is a need to establish appropriate rules that maximize profits while minimizing the risks such as nuisance [16]. Regulations of urban beekeeping are usually motivated by concerns for public safety [7]. To reduce the probability of physical encounter between bees and the people, "Setbacks", which are defined as the distance of hives from the property boundary, adjacent dwelling, public facility, and/or street to raise the flight path upwards, "Flyaway Barriers", which refer to a solid wall or fence, or a dense hedge that helps increase the flight height of bees, as well as the number of hives that owners can keep on their property are common requirements to decrease the potential nuisance effect of beekeeping operations [16].

However, not many municipalities or other governments have set rules for urban beekeeping to date [17]. In the United States and Australia, where there are relatively more rules for urban beekeeping, there are approximately 8-10 regulatory items [16,18]. Among these, in "Lot Size and Colony Density", "Setbacks", "Flyway Barriers", and "Access to Water", we can observe cases where specific standards and criteria have been set [18]. It is unclear whether the present regulations are based on evidence. If not, it is important to understand what measures can be implemented based on science.

There are limited studies examining the effectiveness of regulatory items in urban beekeeping. A study by Garbuzov and Ratnieks [19] is one of the few cases that showed that barriers are effective for flyway control. The purpose of installing setbacks and flyway barriers is to control flyways and to lead the bees above human head height. However, there is a large range in the actual numbers specified. For example, the fence heights can range from 3 to $10 \mathrm{ft}$, and setbacks can range from 1 to $1000 \mathrm{ft}$ [18]. In the regulations developed by local governments, there is no indication of scientific evidence regarding the quantities of regulatory items [18]. Garbuzov and Ratnieks [19] compared the flight height of honey bees with and without barriers and proved that barriers are effective at raising the mean honey bee flight height. However, their study did not provide data from more than $3.6 \mathrm{~m}$ above the ground because they measured the height by video recording honey bees passing across a $3.6 \mathrm{~m}$ high whiteboard. The " $3.6 \mathrm{~m}$ " height appears to be quite insufficient when considering the flying height of honeybees in apiaries. In addition, major parallax error is included by using a single video image. These factors suggest that the observed heights could have contained considerable errors. To evaluate the effect of barrier location and height, multiple fence types and accurate measurement methods should be used in an experimental space with sufficient height.

To date, various methods have already been developed for the spatial localization of flying small animals such as insects in the wild $[20,21]$. In general, visual and camera measurements have weaknesses in terms of accuracy, labor, and observable range. Micro radio-transmitters, in addition to being laborious to install, can affect insect behavior. Radiofrequency identification tags are small and lightweight and can be mounted on insects as large as honey bees, but their relatively short measurable range (usually a few centimeters) limits their use [22]. Harmonic radar can be utilized over long distances, but requires large and expensive equipment, making it less practical. The retroreflector-based tracking system can track the behavior of honeybees within $35 \mathrm{~m}$ at low cost [21], but it is difficult to acquire numerous individuals in a short time. Tauc et al. [23] showed that their light detection and ranging system could accurately detect the spatial location of individual insects flying more than $100 \mathrm{~m}$ away. However, their light detection and ranging system was designed for long-range measurements, and thus has a limited measurement range for close-range apiary-scale measurements. 
At present, there is a gap in the available observation methods for sufficiently measuring the flying altitude of honey bees at the apiary scale. This study aims to address this knowledge gap by examining the effects of fences and setbacks on honey bee flight height, as these are often set within the regulations of urban beekeeping. We also evaluated the methodological implications of using a 3D laser scanner to localize the bees. This method is non-destructive, does not attach observers to the insects, and can accurately acquire a large amount of data in a short time. The data gathered were then statistically analyzed to examine the effects of the fence location and height as well as the distance from the hives on flight height. These findings will provide valuable data for improving urban beekeeping management and implementing evidence-based regulations.

\section{Materials and Methods}

\subsection{Study Area}

We conducted a preliminary experiment and observations from 7:00 to 13:00 on 20 August 2021, in an experimental apiary site located in the center of Japan (Uchino, Oshino-mura village, Minamituru-gun, Yamanashi prefecture, Japan; $35^{\circ} 27^{\prime} 19.44^{\prime \prime} \mathrm{N}$, $\left.138^{\circ} 52^{\prime} 29.73^{\prime \prime} \mathrm{E}\right)$. A half-day experiment was preferred to minimize variables such as, weather, blooming conditions of nectar plants, and honey bee populations. The weather was sunny with occasional clouds and scattered rains at the end of the experiment. This experimental apiary was located on a perfectly flat agricultural field, with an area of $4 \mathrm{~km}$ in the east-west direction and $2 \mathrm{~km}$ in the north-south direction (Figure 1). There are some fields of cabbage and corn around this agricultural field. The elevation is $963 \mathrm{~m}$ and the site is surrounded by mountains with altitudes ranging from 1200 to $1500 \mathrm{~m}$.
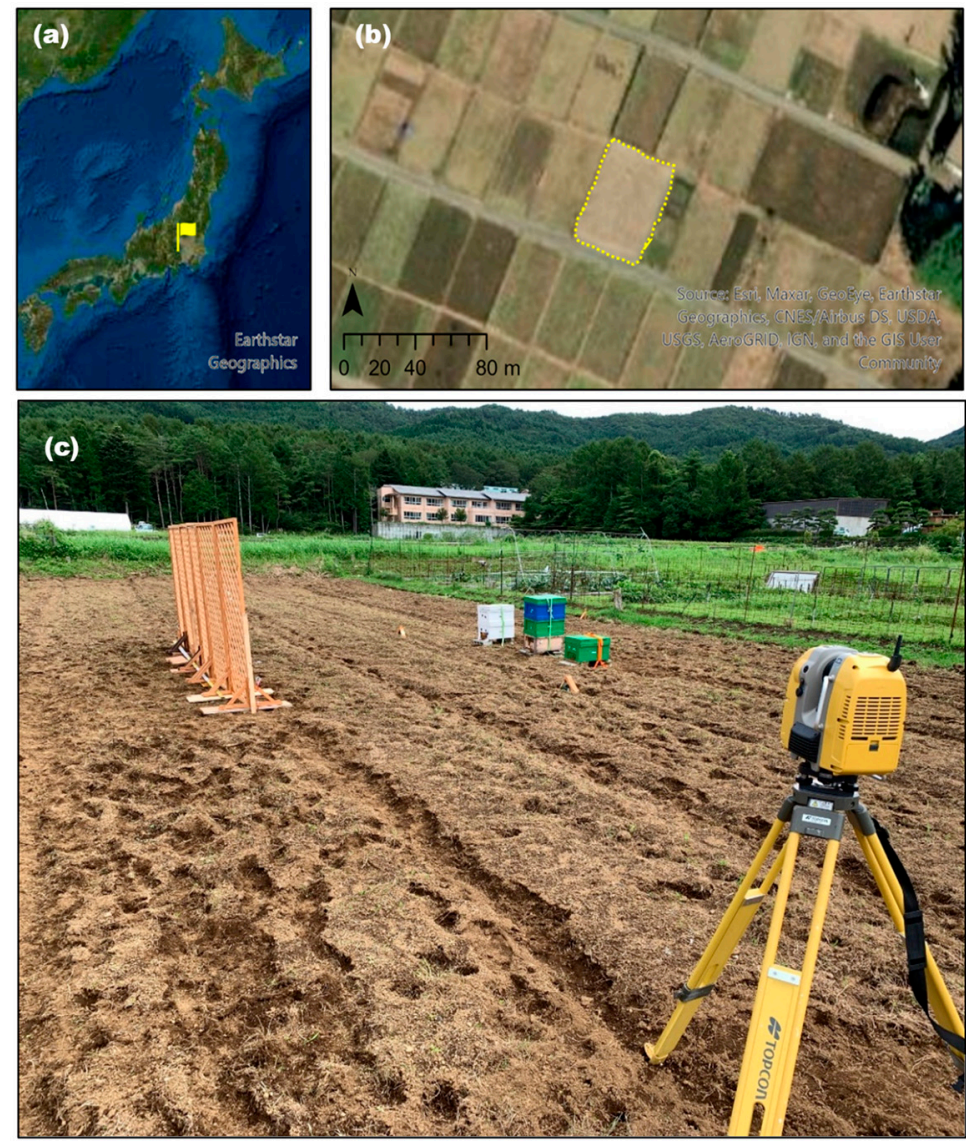

Figure 1. (a) Site of the experimental apiary in Japan; (b) Aerial image of the experimental apiary; (c) Hives and lattice fences installed in the experimental apiary, with a 3D laser scanner set next to the lattice fence (Photographed in the Yamanashi Prefecture, August 2021 by the first author). 


\subsection{Experimental Setup and Procedure}

The experimental apiary site is a $32 \times 42 \mathrm{~m}$ open cropland (Figure 2 ). The weeds were removed and reclaimed two weeks before conducting the study.

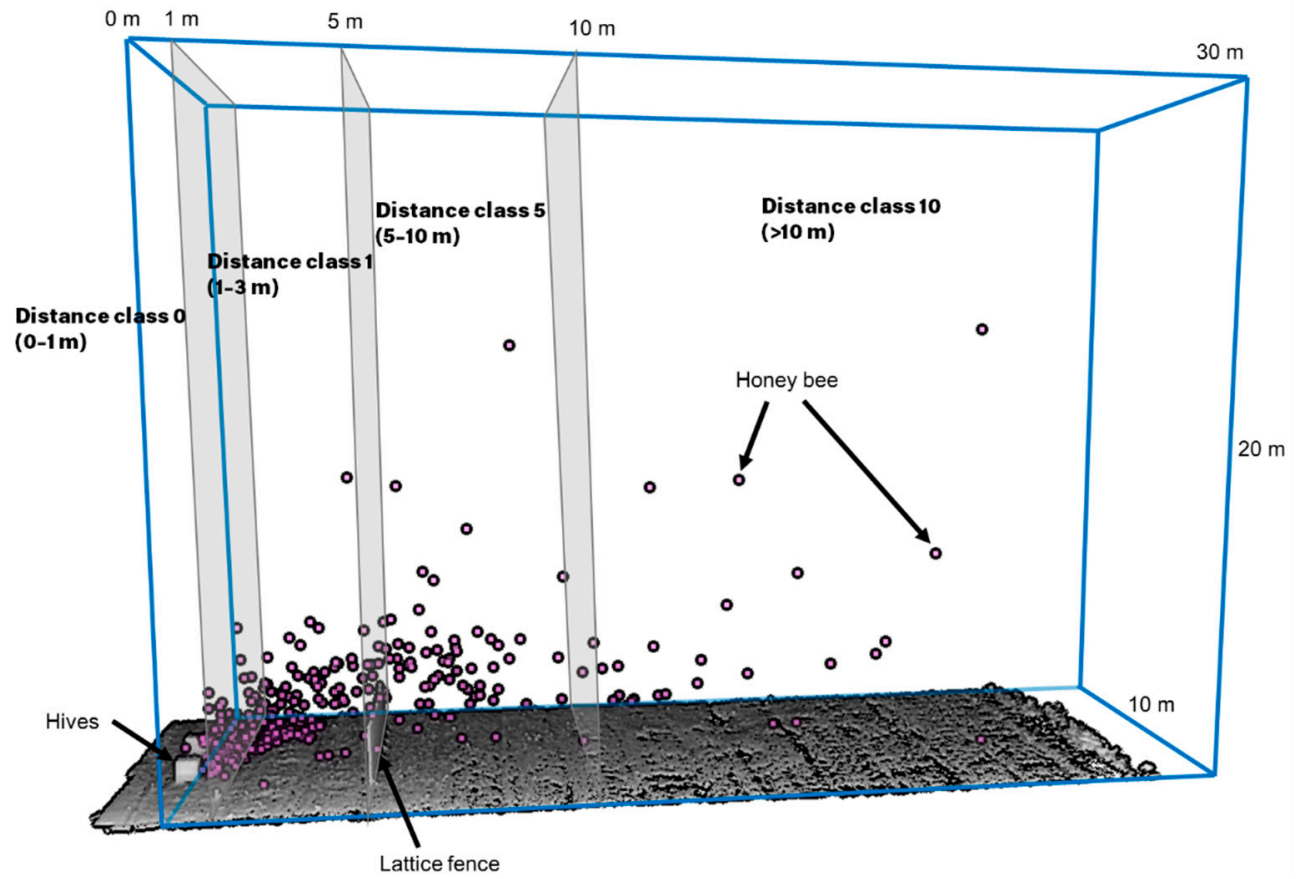

Figure 2. Layout of the experimental apiary. The lattice fence was placed $1 \mathrm{~m}$ or $5 \mathrm{~m}$ from the hive, and the 3D laser scanner was placed directly next to the lattice fence.

Three powerful hives of honey bees (Apis mellifera) were imported from another apiary, which was located $5 \mathrm{~km}$ away from the experimental site, at midnight two days prior to the start of the experiment. These hives were installed on concrete blocks facing west-northwest and kept at a $1 \mathrm{~m}$ distance from each other. The entrances of the hives were located $15 \mathrm{~cm}$ above the ground and opened during the daytime before the day of the study. The area for analyzing the location of honey bees was defined as $30 \mathrm{~m}$ in front of the hive, $10 \mathrm{~m}$ in the lateral direction, and $20 \mathrm{~m}$ towards the sky, using the entrance of the central hive as the origin point of the Euclidean space (Figure 2).

In a previous study [19], no significant difference was recorded between lattice fences and hedges as types of barriers; thus, in this experiment, we only used lattice fence, which was relatively easy to install. We constructed wooden skeleton lattice fences of two heights ("lattice fence $90 \times 180 \mathrm{~cm}$ ", Cain Co. Ltd., Honjo-shi, Saitama, Japan) as barriers, namely low and high. The low barriers had a height of $90 \mathrm{~cm}$ and a width of $540 \mathrm{~cm}$ while the high barriers had a height of $180 \mathrm{~cm}$ and a width of $540 \mathrm{~cm}$. These heights were chosen based on the comprehensive review [18] conducted prior to this preliminary experiment. Based on the search of urban beekeeping in the United States, most cases have heights ranging from 90 (180 cases) to $180 \mathrm{~cm}$ (156 cases) [18].

These fences were installed within a few minutes and placed at $1 \mathrm{~m}$ or $5 \mathrm{~m}$ from the hive entrance (Figure 2). Honeybees memorize the height of the barrier, which can influence the flying height [19]. Thus, to minimize the effect of memory, five different fence types were installed, as reflected in Table 1: no fence, far low, far high, near low, and near high. Each of the lattice fences had gaps through which bees could pass. However, we rarely observed bees passing through the fences throughout the experiment. Although the lattice fence used in this experiment has gaps, the effect of raising the flight heights of bees can be enhanced by using a solid wall or dense vegetation. 
Table 1. Fence type and experimental sequence.

\begin{tabular}{cccc}
\hline Fence Type & $\begin{array}{c}\text { Distance from } \\
\text { Hives }\end{array}$ & Height of Barrier & $\begin{array}{c}\text { Experimental Sequence } \\
\text { and Time }\end{array}$ \\
\hline A & None & None & 1st (7:34-) \\
B & Far $(5 \mathrm{~m})$ & Low $(0.9 \mathrm{~m})$ & 2nd $(8: 46-)$ \\
C & Far $(5 \mathrm{~m})$ & High $(1.8 \mathrm{~m})$ & 3rd (9:52-) \\
D & Near $(1 \mathrm{~m})$ & Low $(0.9 \mathrm{~m})$ & 4th $(11: 15-)$ \\
E & Near $(1 \mathrm{~m})$ & High $(1.8 \mathrm{~m})$ & 5th $(12: 20-)$ \\
\hline
\end{tabular}

To determine any data error caused by animals other than honeybees, we conducted a flying animal capture test the day before the experiment. In this test, we installed an insect net with a diameter of $50 \mathrm{~cm}$ on a pole $250 \mathrm{~cm}$ in length and swept while walking 500 times at various heights to capture flying animals.

A total of eighteen individuals of six insect species were captured (Table 2). All insects except Apis mellifera and Vespa simillima were smaller than $2 \mathrm{~mm}$, so they would not be detected by the laser beam profiler. During the experiment, butterflies (Nymphalidae gen. sp.), beetles (Scarabaeidae gen. sp.), and barn swallows (Hirundo rustica) passed through the experimental area less than five times. Hence, most of the plots detected by the laser scanner in this study were considered as honey bees.

Table 2. List of insects in the capture test. Sweeping was conducted 500 times in the experimental apiary.

\begin{tabular}{ccc}
\hline Scientific Name & Body Size (mm) & Number of Individuals (\%) \\
\hline Apis mellifera & $12-14$ & $13(72 \%)$ \\
Vespa simillima & 22 & $1(5.6 \%)$ \\
Psilopa polita & 2 & $1(5.6 \%)$ \\
Phoridae gen. sp. & 1 & $1(5.6 \%)$ \\
Drosophilidae gen. sp. & 1 & $1(5.6 \%)$ \\
Aphididae gen. sp. & 1 & $1(5.6 \%)$ \\
\hline
\end{tabular}

\subsection{Measuring Flight Heights}

The locations of honey bees were detected using a GLS-2200 laser scanner (Topcon Corporation, Tokyo, Japan), which was placed just beside the barriers outside the analysis space $(10 \times 30 \times 20 \mathrm{~m})$. This machine was developed to create high quality 3D images by irradiating more than 100,000 lasers per second in all directions. Due to the high density of lasers, flying objects in space can be detected, but such data are usually considered as noise. We used these noises as the location data of the honey bees.

Scanning was conducted using the high-speed mode, with 120,000 laser points/s (Class 3R) covering the entire experimental area. The laser was irradiated at a density of $12.5 \mathrm{~mm}$ and a distance of $10 \mathrm{~m}$ from the instrument. Since the size of a honey bee is approximately $12-14 \mathrm{~mm}$, we considered that one individual would correspond to one point, but this has not been verified.

Though a single scan can capture the entire apiary, we completed 24 scans for each of the five fence types to increase the number of samples. Only 22 scans were completed for fence type 5 due to rain. Each scan took approximately $1 \mathrm{~min}$ and $30 \mathrm{~s}$, and the data from the 24 or 22 scans were merged into one for each fence type in the application. The number of plots of honey bees captured by the 3D scanner is shown in Table 3 . The obtained point cloud data were manually segmented into bees and background using the point cloud processing application QuickStitch (EIVA, Skanderborg, Denmark). The point cloud data were then converted to relative locations from the origin, and the distances from the hive were classified into four categories (distance0: 0-1 m, distance1: 1-5 m, distance5: 5-10 m, and distance10: >10 m) for statistical analysis. 
Table 3. Number of honey bee plots observed by the 3D scanner.

\begin{tabular}{cccc}
\hline Fence Type & $\begin{array}{c}\text { Height and } \\
\text { Distance }\end{array}$ & $\begin{array}{c}\text { Number of Honey } \\
\text { Bee Plots }\end{array}$ & $\begin{array}{c}\text { Number of Honey Bee Plots } \\
\text { in the Analysis Space } \\
\text { (W 10 m } \times \text { L 30 m } \times \text { H 20 m) }\end{array}$ \\
\hline A & No barrier & 2007 & 845 \\
B & Far-Low & 3004 & 752 \\
C & Far-High & 1190 & 634 \\
D & Near-Low & 1099 & 633 \\
E & Near-High & 1329 & 671 \\
\hline Total & - & $\mathbf{8 6 2 9}$ & $\mathbf{3 5 3 5}$ \\
\hline
\end{tabular}

\subsection{Statistical Analyses}

The data collected were used to analyze the effects of the distance between the hive and the barrier and those of the height of the barrier on the flight height of the honey bees. All statistical analyses were performed with EZR [24], which is a modified version of $R$ commander designed to provide statistical functions frequently used in biostatistics.

Friedman's test was used to determine the differences between the fence types (A-E) and distance classes $(0,1,5$ and 10$)$. When statistically significant differences were detected among the groups, a Bonferroni correction was used for multiple comparisons (group to group). The significance level was set at $5 \%$.

\section{Results}

Preliminary analysis was conducted to evaluate the null hypothesis of this study, which states that the population followed a normal distribution. Based on the Shapiro-Wilk normality test, all combinations excluding one case (fence type $\mathrm{A} \times$ distance 10 ) were not normally distributed $(p<0.05)$, thus rejecting the null hypothesis. The same test was conducted for the flight height dataset and similar results were obtained, rejecting the null hypothesis. Based on the normality test results, we used non-parametric methods to further analyze the data.

The Friedman test performed for fence type and distance class showed significant differences between all types and classes $(p<0.001)$. Bonferroni's multiple comparisons were then conducted as a post-hoc test. For fence type, fence type $\mathrm{C}$ had a lower flying height than that of all the other fence types ( $p<0.001$, Figure 3a). For the distance class, all combinations were significantly different $(p<0.001$, Figure $3 b)$, and the flying height increased with the distance from the hives.

(a)

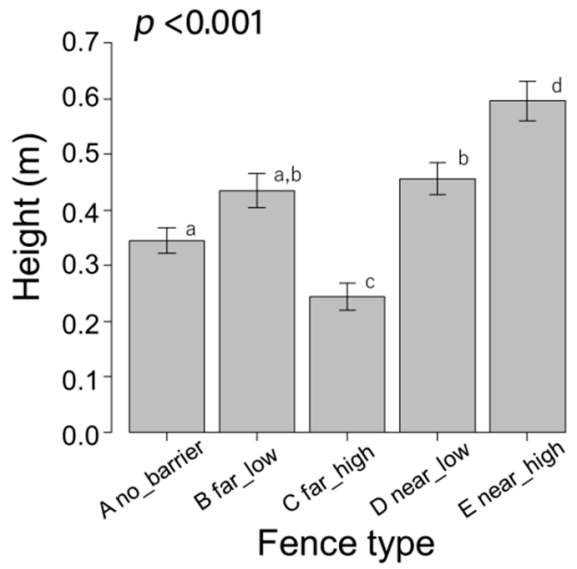

(b)

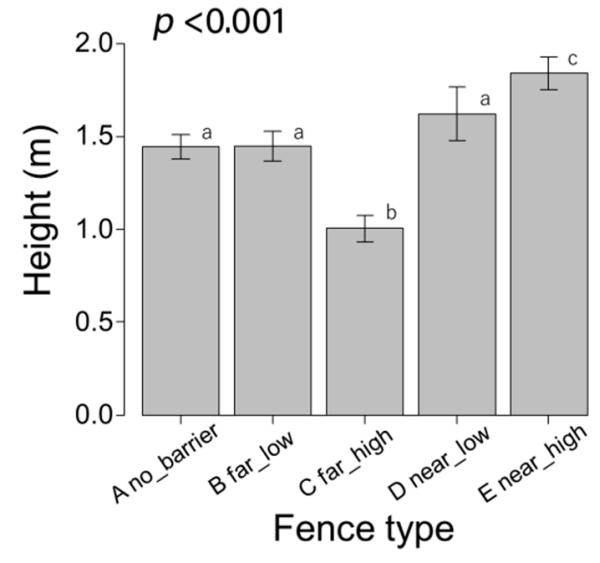

Figure 3. Difference in flying height by (a) fence type and (b) distance class. Letters above the error bars represent the results of Bonferroni's post-hoc pairwise comparison test. Error bar heights are means \pm standard error. 
Therefore, to examine the effect of fence type, the data were divided into distance classes, and the Kruskal-Wallis test was conducted within the same distance class. When significant differences were observed, the Bonferroni multiple comparison test was conducted.

We conducted the Kruskal-Wallis test based on the conditions set, and the results showed a significant difference for distance class $0(p<0.001)$ (Figure 4a), distance class 1 $(p<0.001)$ (Figure $4 b)$, and distance class $5(p<0.001)$ (Figure $4 c)$. However, for distance class 10, the results did not show any significant difference $(p=0.69)$ (Figure $4 \mathrm{~d})$. Subsequently, Bonferroni's post-hoc pairwise comparison tests were performed on combinations for which significant differences were detected $(p<0.05)$. For distance class $0(0-1 \mathrm{~m}$ from the hives), the results showed a significant difference in fence types $\mathrm{D}(\mathrm{D}>\mathrm{A}, p=0.025)$, $\mathrm{E}(\mathrm{E}>\mathrm{A}, p<0.001)$, and $\mathrm{C}(\mathrm{C}<\mathrm{A},<0.001)$ (Figure $4 \mathrm{a})$. For distance class $1(1-5 \mathrm{~m}$ from the hives), the results showed a significant difference in fence types $\mathrm{E}(\mathrm{E}>\mathrm{A}, p<0.001)$ and $\mathrm{C}(\mathrm{C}<\mathrm{A}, p<0.001)$ (Figure $4 \mathrm{c})$. For distance class 5 (5-10 $\mathrm{m}$ from the hives), the results showed a significant difference in fence types $\mathrm{E}(\mathrm{E}>\mathrm{A}, p<0.022)$ and $\mathrm{C}(\mathrm{C}>\mathrm{A}, p<0.001$ and $\mathrm{C}>\mathrm{B}, p<0.001$ ) (Figure $4 \mathrm{c}$ ).

\section{(a)}

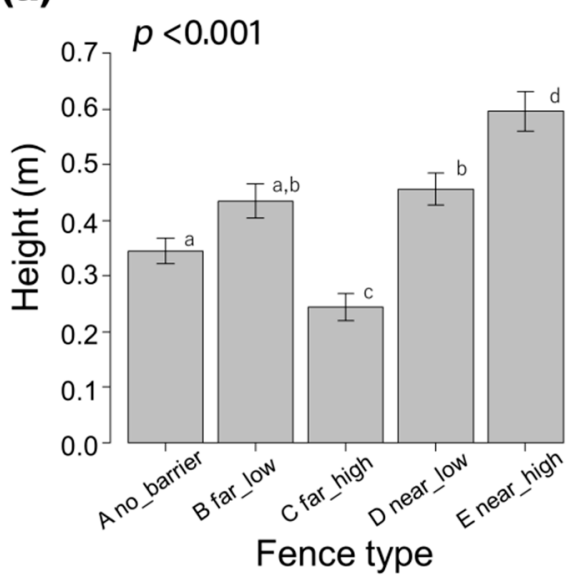

(c)

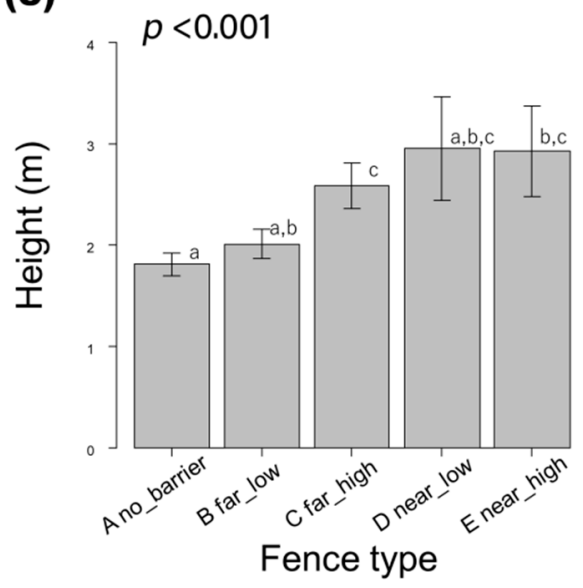

(b)

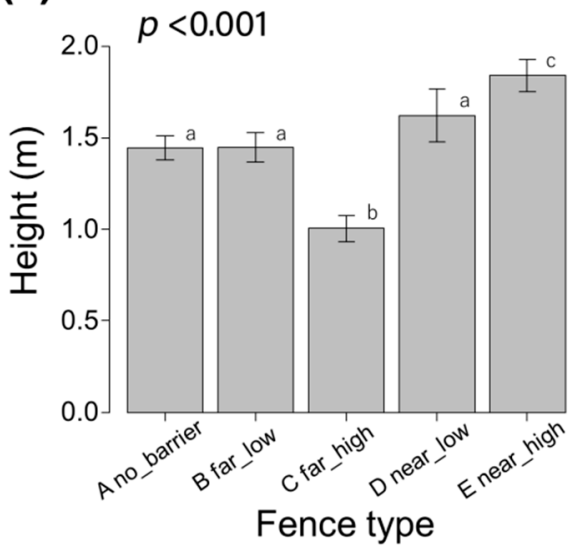

(d)

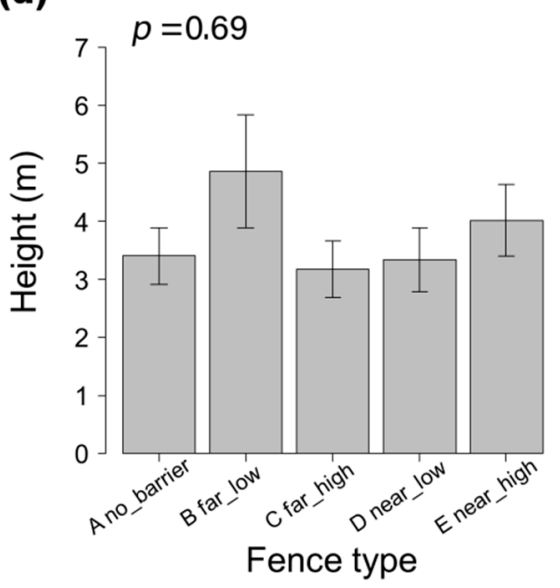

Figure 4. Effect of fence type on flight altitude. Average flying height for (a) distance class $0(0-1 \mathrm{~m}),(\mathbf{b})$ distance class $1(1-5 \mathrm{~m}),(\mathbf{c})$ distance class $5(5-10 \mathrm{~m})$, and (d) distance class $10(>10 \mathrm{~m})$. (a-c) showed significant differences among fence types, while (d) showed no significant differences. Letters above the error bars represent the results of Bonferroni's post-hoc pairwise comparison test. Bar heights are the means \pm standard error.

In summary, the $1.8 \mathrm{~m}$ high barrier was effective at leading the honey bees to fly higher. The $0.9 \mathrm{~m}$ high barrier had a similar effect, but a less effective one. The flight height increased with distance from the hives, and the effect of the barriers became less significant when the honey bees were more than $10 \mathrm{~m}$ away from the hives. 


\section{Discussion}

\subsection{Effectiveness of the Barriers (Location and Height of the Lattice Fence)}

The purpose of this study is to reveal the effect of barrier installation on the flight height of honey bees. The three evaluated parameters, which included the fence position, height, and distance from the hives, were found to affect the flight height of honey bees. The barriers were effective at increasing the flight height both at 1 and $5 \mathrm{~m}$ from the hives. However, the honey bees will most likely increase their flight height with distance from the hives regardless of the presence of the fences [19]. Therefore, barriers are more likely to be effective if placed closer to the hives.

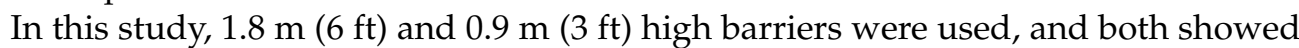
positive effects on the flight height, although the effect of the $1.8 \mathrm{~m}$ barrier was greater. Fence type $\mathrm{E}$ ( $1.8 \mathrm{~m}$ barrier placed $1 \mathrm{~m}$ away from the front of the hives) showed an average flight height of $1.84 \mathrm{~m}( \pm 0.09$, standard error) at distance class 1 (1-5 $\mathrm{m}$ from the hives), and fence type $\mathrm{C}$ ( $1.8 \mathrm{~m}$ barrier placed $5 \mathrm{~m}$ away from the front of the hives) showed an average flight height of $2.59 \mathrm{~m}( \pm 0.22$, standard error) at distance class 5 (5-10 $\mathrm{m}$ from the hives). Based on these results, it can be expected that this system will be effective at preventing nuisance regardless of its location. These further suggest that fences installed as close as $1 \mathrm{~m}$ from the hives are sufficiently effective. These findings can have regulatory implications for designing apiaries in urban spaces, where the location of fences is often restricted.

For all five fence types, the flying height tended to increase with distance. Even in the case of no barrier (fence type A), the average height in distance classes $5(5-10 \mathrm{~m})$ and $10(>10 \mathrm{~m})$ was 1.81 and $3.41 \mathrm{~m}$, respectively. This indicates that even without a fence, if there is enough distance to the property boundary, nuisance to people is unlikely to occur, illustrating the effectiveness of the setback.

If the setback is too large, it could be a disincentive for urban beekeeping. The City of Ontario, Canada, has a 30-m setback, while the Osaka Prefecture, Japan, has a 20-m setback requirement, which essentially prohibits urban beekeeping $[9,18]$. It may be worthwhile for these cities to re-examine whether they can make their setback provisions shorter.

In conclusion, this study confirmed that using 3D scanners represents an effective method for measuring small flying insects. The flyway was raised by installing a lattice fence. Higher fences can increase the flying height of honey bees. A fence $1 \mathrm{~m}$ from the hive was adequately effective at raising the flying height. Moreover, the flight heights tended to increase as the bees moved further away from the hive, and the effect of the barrier could not be confirmed when the distance was $>10 \mathrm{~m}$.

\subsection{Methodological and Management Implications}

Various methods have been used to record the location of flying insects. For example, attaching radio transmitters and radio-frequency identification tags have weaknesses such as the influences on the insects, time required for attaching, limited number of samples, and short observable distance [19]. Visual and video camera analyses are also disadvantageous in terms of the accuracy and time required [21]. The present study used a 3D laser scanner, which has rarely been used for determining the location of flying insects. Using this device, we were able to obtain 8529 points of highly accurate flight location data in about $5 \mathrm{~h}$, without attaching any sensing devices to the bees. Furthermore, the data can be analyzed and processed in just a few hours, which is much faster than analyzing video images or using radio transmitters. With a more multifunctional laser device, it may be possible to identify species and analyze their migration speed and direction.

Urban beekeeping brings a variety of benefits, but also risks, so it is crucial that appropriate regulations exist $[10,18]$. Existing regulations on urban beekeeping often include regulatory items, such as the number and density of hives, water supply, as well as barriers and setbacks. The effects of barriers, however, have rarely been tested [19]. The approach of this study will be helpful to examine and provide evidence for the effects of these regulatory items. 


\subsection{Limitations and Future Studies}

Though this study is a preliminary experiment, significant results were obtained. Quite simply, both the barrier and the setback had the effect of increasing the flying height. Nevertheless, future studies can increase the number of experiments, days, and sites, as Garbuzov and Ratnieks [19] observed. Long-term effects of fencing relative to different seasons can also be investigated.

Another limitation of this work is the accuracy of detecting flying objects other than honey bees flying more than $3 \mathrm{~m}$ above the ground. To improve this methodological flaw, it is recommended to use a more multifunctional laser device such as wing-beat modulation LiDAR. These devices have been successfully used in $[23,25]$.

Moreover, this study only focused on the average flying height of honey bees. There might be a number of honey bees flying more than the average height, which could bother people. Thus, increasing the number of flight variations (e.g., lower altitudes) in future studies is recommended. Garbuzov and Ratnieks [19] argued that honey bees memorize the height of the barriers, so the raising effect is unlikely to appear immediately after the installation of the barriers. Contrastingly, the results of this study revealed that the barrier raised the flight height even immediately after installation. In the future, we plan to conduct more long-term observations, taking into account the memory effects, not only immediately after the installation of the fence.

The regulations on urban beekeeping may not be based on scientific evidence, although there are various provisions such as the number of hives, density, setbacks, and barrier height. It is not recommended that over-regulation reduces the various benefits that urban beekeeping could provide. Governments need to develop rules to enable urban beekeeping while ensuring safety [16], but more work needs to be done, e.g., the application of environmental DNA analysis to honey bees' behavior [26] to provide a scientific basis for the regulations, as was done in this preliminary study.

Future studies could look into socio-ecological contexts of urban beekeeping, e.g., [17,27]. Fostering collaborations among different stakeholders (e.g., citizens, research institutions) is important to secure commitments to urban beekeeping in the context of pollinator conservation $[15,28]$. However, at the local scale, collaborations among different sectors are common challenges in biodiversity monitoring and management practices [29,30]. Nevertheless, from methodological perspectives, stakeholders' perceptions in urban-rural settings are found to record appropriate information regarding the environment (e.g., [31-33]) and effective in providing feedback to management policies (e.g., [34-36]) for future development.

Author Contributions: Conceptualization, R.K.; methodology, T.M.; software, T.M.; validation, T.M.; investigation, T.M.; writing—original draft reparation, T.M.; writing-review and editing, T.M. and R.K.; visualization, T.M.; supervision, R.K.; project administration R.K.; funding acquisition, R.K. and T.M. All authors have read and agreed to the published version of the manuscript.

Funding: This work was supported by JSPS KAKENHI Grant Numbers JP21K18456; JP20K12398; JP16KK0053; JP17K02105; JST RISTEX Grant Number JPMJRX20B3. This work was also supported by IDEA Consultants, Inc.

Institutional Review Board Statement: Not applicable.

Informed Consent Statement: Not applicable.

Data Availability Statement: Not applicable.

Acknowledgments: The authors would like to thank Jay Mar D. Quevedo, Yuta Uchiyama, Yoshitaka Miyake, Kenichiro Nishibayashi, Naoki Koyanagi, Hiroshi Asanuma, Ryosuke Komatsu, Satoshi Kashiwabara, and Keita Kosoba for their continuous support.

Conflicts of Interest: The authors declare no conflict of interest. 


\section{References}

1. Ayan, S.; Ayan, Ö.; Altunel, T.; Yer, E.N. Honey forests as an example of agroforestry practices in Turkey. For. Ideas 2014, 20, 141-150.

2. Bradbear, N. Bees and Their Role in Forest Livelihoods: A Guide to the Services Provided by Bees and the Sustainable Harvesting, Processing and Marketing of Their Products; Food and Agriculture Organization of the United Nations: Rome, Italy, 2009.

3. IPBES. Summary for Policymakers of the Assessment Report of the Intergovernmental Science-Policy Platform on Biodiversity and Ecosystem Services (IPBES) on Pollinators, Pollination and Food Production. Available online: https://www.researchgate.net/ publication/329503936_Summary_for_policymakers_of_the_assessment_report_of_the_Intergovernmental_Science-Policy_ Platform_on_Biodiversity_and_Ecosystem_Services_IPBES_on_pollinators_pollination_and_food_production (accessed on 31 December 2019)

4. Toni, C.; Djossa, B.; Yedomonhan, H.; Zannou, E.; Mensah, G. Western honey bee management for crop pollination. Afr. Crop. Sci. J. 2018, 26, 1-17. [CrossRef]

5. Hoover, S.E.; Ovinge, L.P. Pollen Collection, Honey Production, and Pollination Services: Managing Honey Bees in an Agricultural Setting. J. Econ. Entomol. 2018, 111, 1509-1516. [CrossRef]

6. Watson, K.; Stallins, J.A. Honey Bees and Colony Collapse Disorder: A Pluralistic Reframing. Geogr. Compass 2016, 10, $222-236$. [CrossRef]

7. Moore, L.J.; Kosut, M. Buzz: Urban Beekeeping and the Power of the Bee; New York University Press: New York, NY, USA, 2013.

8. Henry, M.; Béguin, M.; Requier, F.; Rollin, O.; Odoux, J.-F.; Aupinel, P.; Aptel, J.; Tchamitchian, S.; Decourtye, A. A Common Pesticide Decreases Foraging Success and Survival in Honey Bees. Science 2012, 336, 348-350. [CrossRef]

9. Askham, B. Urban buzz. Sanctuary Mod. Gr. Homes 2013, 25, 76-79.

10. Egerer, M.; Kowarik, I. Confronting the Modern Gordian Knot of Urban Beekeeping. Trends Ecol. Evol. 2020, 35, 956-959. [CrossRef] [PubMed]

11. Baldock, K. Opportunities and threats for pollinator conservation in global towns and cities. Curr. Opin. Insect Sci. 2020, 38, 63-71. [CrossRef]

12. Skelton, J. Adventures in Urban Beekeeping. Briarpatch 2006, 35, 14-17.

13. Wilk, B.; Rebollo, V.; Hanania, S. A Guide for Pollinator-Friendly Cities: How Can Spatial Planners and Land-Use Managers Create Favourable Urban Environments for Pollinators? Available online: https://www.iucn.org/sites/dev/files/local_authorities_ guidance_document_en_compressed.pdf (accessed on 30 October 2021).

14. City News Service Backyard Beekeeping OK'd by City of Los Angeles-Daily News. Available online: https:/ /www.dailynews. com/2015/10/14/backyard-beekeeping-okd-by-city-of-los-angeles / (accessed on 13 January 2020).

15. Gallay, C. Beeware of the Consequences: The Importance of Urban Apiaries and Environmental ADR. Cardozo J. Confl. Resol. 2018, 20, 417-442.

16. Salkin, P.E. Honey, It's All the Buzz: Regulating Neighborhood Beehives. BC Envtl. Aff. L. Rev. 2012, 39, 55-71.

17. Larson, K.L.; Andrade, R.; Nelson, K.C.; Wheeler, M.M.; Engebreston, J.M.; Hall, S.J.; Avolio, M.L.; Groffman, P.M.; Grove, M.; Heffernan, J.B.; et al. Municipal regulation of residential landscapes across US cities: Patterns and implications for landscape sustainability. J. Environ. Manag. 2020, 275, 111132. [CrossRef] [PubMed]

18. Matsuzawa, T.; Kohsaka, R. Status and Trends of Urban Beekeeping Regulations: A Global Review. Earth 2021, 2, 933-942. [CrossRef]

19. Garbuzov, M.; Ratnieks, F.L.W. Lattice fence and hedge barriers around an apiary increase honey bee flight height and decrease stings to people nearby. J. Apic. Res. 2014, 53, 67-74. [CrossRef]

20. Reynolds, D.; Riley, J. Remote-sensing, telemetric and computer-based technologies for investigating insect movement: A survey of existing and potential techniques. Comput. Electron. Agric. 2002, 35, 271-307. [CrossRef]

21. Smith, M.T.; Livingstone, M.; Comont, R. A method for low-cost, low-impact insect tracking using retroreflective tags. Methods Ecol. Evol. 2021, 12, 2184-2195. [CrossRef]

22. Nunes-Silva, P.; Hrncir, M.; Guimarães, J.T.; Arruda, H.; Costa, L.; Pessin, G.; Siqueira, J.O.; de Souza, P.; Imperatriz-Fonseca, V.L. Applications of RFID technology on the study of bees. Insectes Sociaux 2019, 66, 15-24. [CrossRef]

23. Tauc, M.J.; Fristrup, K.M.; Repasky, K.S.; Shaw, J.A. Field demonstration of a wing-beat modulation lidar for the 3D mapping of flying insects. OSA Contin. 2019, 2, 332-348. [CrossRef]

24. Kanda, Y. Investigation of the freely available easy-to-use software 'EZR' for medical statistics. Bone Marrow Transplant. 2013, 48, 452-458. [CrossRef]

25. Chen, Y.; Why, A.; Batista, G.; Mafra-Neto, A.; Keogh, E. Flying Insect Classification with Inexpensive Sensors. J. Insect Behav. 2014, 27, 657-677. [CrossRef]

26. Matsuzawa, T.; Kohsaka, R.; Uchiyama, Y. Application of Environmental DNA: Honey Bee behavior and Ecosystems for Sustainable Beekeeping. In Modern Beekeeping-Bases for Sustainable Production; In Tech Open: Rijeka, Croatia, 2020. [CrossRef]

27. Sponsler, D.B.; Bratman, E.Z. Beekeeping in, of or for the city? A socioecological perspective on urban apiculture. People Nat. 2021, 3, 550-559. [CrossRef]

28. Nicholls, A.A.; Epstein, G.B.; Colla, S.R. Understanding public and stakeholder attitudes in pollinator conservation policy development. Environ. Sci. Policy 2020, 111, 27-34. [CrossRef] 
29. Uchiyama, Y.; Kohsaka, R. Application of the City Biodiversity Index to populated cities in Japan: Influence of the social and ecological characteristics on indicator-based management. Ecol. Indic. 2019, 106, 105420. [CrossRef]

30. Shih, W.-Y.; Mabon, L.; de Oliveira, J.A.P. Assessing governance challenges of local biodiversity and ecosystem services: Barriers identified by the expert community. L. Use Policy 2020, 91, 104291. [CrossRef]

31. Uchiyama, Y.; Kohsaka, R. Strategies of Destination Management Organizations in Urban and Rural Areas: Using Text Analysis Method for SWOT Descriptions at Meta-level. Int. J. Hosp. Tour. Adm. 2021, 1, 1-19. [CrossRef]

32. Quevedo, J.M.D.; Uchiyama, Y.; Kohsaka, R. Linking blue carbon ecosystems with sustainable tourism: Dichotomy of urban-rural local perspectives from the Philippines. Reg. Stud. Mar. Sci. 2021, 45, 101820. [CrossRef]

33. Imai, H.; Nakashizuka, T.; Kohsaka, R. An analysis of 15 years of trends in children's connection with nature and its relationship with residential environment. Ecosyst. Health Sustain. 2018, 4, 177-187. [CrossRef]

34. Kohsaka, R.; Park, M.S.; Uchiyama, Y. Beekeeping and honey production in Japan and South Korea: Past and present. J. Ethn. Foods 2017, 4, 72-79. [CrossRef]

35. Quevedo, J.M.D.; Uchiyama, Y.; Kohsaka, R. A blue carbon ecosystems qualitative assessment applying the DPSIR framework: Local perspective of global benefits and contributions. Mar. Policy 2021, 128, 104462. [CrossRef]

36. Kohsaka, R. Developing biodiversity indicators for cities: Applying the DPSIR model to Nagoya and integrating social and ecological aspects. Ecol. Res. 2010, 25, 925-936. [CrossRef] 